character and structural context of the chemical bonds being broken. Ultimately the analysis generates a 'tree' of possible synthetic intermediates.

The obvious advantage of the approach was that it made synthesis systematic. Nevertheless, it was only after Corey had successfully used it to synthesize a host of natural products that it became widely accepted. Now it is standard laboratory practice. "No one embarks on a synthesis these days without applying the retrosynthetic method", says John Mann, reader in organic chemistry at the University of Reading.

Corey was also quick to realize the potential power of the computer as an aid to analysing the hundreds of intermediates that can result from a retrosynthesis. In recent years, programmes have emerged that not only generate intermediates but offer guidance on picking the simplest route through them to the target AUSTRALIAN UNIVERSITIES

\section{First strike over pay and conditions}

\section{Melbourne}

Australian university and college staff last week held their first one-day strike in a campaign to protest against poor career structure and to demand wage rises. The 4,500 academic staff who went on strike warned that unless their wage claims were met by 1 November, they would take further action including a refusal to release examination results or enrol students.

The three unions involved, the Federation of Australian University Staff Associations (FAUSA), the Australian Teachers Union and the Union of Australian College Academics, representing 35 colleges and universities, want average wage increases of 17 per cent in order to makes salaries competitive with those in private industry and at universities elsewhere. The increase would also bring academic salaries into line with the increased rates paid to scientists at the Commonwealth Scientific and Industrial Research Organization (CSIRO).

According to Di Zetlin, general secretary of FAUSA, wage increases are necessary to attract the academics needed to replace the large number who will retire in the next decade. "With an expected shortfall of 10,000 academics by the year 2000, the bottom line is that we must create more attractive salaries and career structures. Most of those retiring will be senior academics."

The unions are seeking a common salary scales and career structures for all academics in Australian tertiary institutions, an increase in tenured employment in universities, and a removal of barriers to promotion within the different salary ranges.

In October last year, the federal cabinet agreed to support an average award insame coin. molecule.

Born in 1928, Corey received his bachelor's degree from the Massachusetts Institute of Technology in 1948 and doctorate there two years' later. From 1951 to 1959 he rose through the ranks at the University of Illinois before moving to Harvard where he has been ever since. $\mathrm{He}$ is the sixth Harvard professor to win the prize in Chemistry, and his award brings the total number of Nobel laureates on the Harvard faculty to 18 . It is also the latest in a run of awards to Americans.

Finally, for scientists who consider teaching to be the bugbear of academic life, this year's chemistry prize holds a moral: it was Corey's quest for a more logical way of teaching organic synthesis that originally shaped his thinking about the subject. He has been much quoted since for maintaining that teaching and fundamental research are two sides of the

David Concar

crease for academics of 6.7 per cent. But CSIRO scientists, traditionally receiving salaries equivalent to those given to academics, obtained increases of between 5 per cent and 10 per cent above the cabinet allocation.

According to Simon Marginson, research officer for FAUSA, career structures also need to be reviewed. Junior academics are hardest hit, with fewer than one in ten in permanent employment, and many working on a casual basis without benefits. FAUSA is seeking increases in the number of tenured positions open to junior academics.

The Australian Higher Education Industrial Association (AHEIA), representing the employers, admits that there is both a case for a "major upgrading in salaries", and for a "greater proportion of staff having tenure at junior levels", according to Professor David Penington, president of AHEIA.

The biggest obstacle to negotiations between the unions and employers now seems to be the employers' demand that salary rises be linked to performance. In the present system, academics are assessed only when applying for promotion to a higher grade. Movement and salary increas: within each grade, however, is automatic. The universities are trying to introduce a "soft bar" which can prevent a person progressing within a group if his or her work is not up to standard. Marginson sees this "soft bar" as "managerial interference and a way to delay the promotion of academics". Penington, however, points out that "all CSIRO's officers are continually assessed at every level. If the unions want us to follow the CSIRO system, then they must be prepared to undergo performance appraisal".

\section{Another pulsar bites the dust}

\section{São Paulo \& Washington}

THE source of periodic brightness variations that led a team of Brazilian astronomers to announce that they had at last found a pulsar in the remnant of supernova 1987A was traced, a few days after the claim was made, to mechanical vibrations in the telescope. This is the second spurious 'pulsar' to have been found in SN1987A; the first, pulsing at a barely credible frequency of $2,000 \mathrm{~Hz}$ (Nature $\mathbf{3 3 8}, 234$; 1989) was eventually ascribed to stray emissions from nearby electronics. The latest non-pulsar was more shortlived, but the rumours were substantial enough to be noted in these pages (see Nature 347, 511; 1990)

The Brazilian team, led by J. E. Steiner of the University of São Paulo, asked the Center for Astrophysics (CfA) in Cambridge, Massachusetts, to transmit an International Astronomical Union (IAU) circular to alert the astronomical community of their discovery. But according to Daniel Green of the CfA, the details were not wholly convincing, and a request for more information was sent to Steiner; he responded by asking for the IAU circular not to be sent, as unspecified problems had turned up.

Although the Brazilians, who made their observations on a 1.6-metre University of São Paulo telescope, checked their instrumentation by ascertaining that stars near the supernova remnant showed no pulsation, they later realized that their photometric detector was being confused by light from the nebula around the supernova site, and sent into some kind of instability. More negative evidence came from the European Southern Observatory (ESO) in Chile, where H. Ögelmann and C. Gouisses were also looking for a pulsar. On the night of 28 September, when Steiner's team believed it had seen something, they found no optical pulsations.

John Danziger, an astronomer at ESO headquarters in Munich, says there is solid evidence for a source of energy in SN1987A in addition to the still-decaying radioactive debris of the explosion: its luminosity has been falling less rapidly than the simple exponential curve that radioactivity alone would produce. Energy coming from material falling onto a compact central object such as a neutron star can reasonably explain the observations, but the case that this is indeed a pulsar is only inferential. The excess brightness is entirely at infrared wavelengths, suggesting that energy from within is being reprocessed by the surrounding cocoon of dust, concealing the source from direct observation. 